\title{
Mental Health Promotion: Prevention of Problematic Internet Use among
}

\section{Adolescents}

\author{
Andrés Fontalba-Navas ${ }^{1}$, Macarena Marin-Olalla ${ }^{1}$, Virginia Gil-Aguilar ${ }^{2}$, José Rodriguez-Hurtado ${ }^{1}$, Gerardo Ríos-García ${ }^{1}$ and Jose Miguel Pena-Andreu ${ }^{3}$ \\ ${ }^{1}$ Mental Health Unit Healthcare Management Area Norte Almería, Andalusian Health Service, Spain \\ ${ }^{2}$ Cuevas del Almanzora Primary Care Center, Northern Area Health Management Almeria, Andalusian Health Service, Spain \\ ${ }^{3}$ Department of Psychiatry and Physiotherapy, Malaga University, Spain
}

*Corresponding author: Andrés Fontalba-Navas et al. Mental Health Unit Healthcare Management Area Norte Almería, Andalusian Health Service, Spain, Tel: 34619674454; E-mail: andresfontalba@gmail.com

Received Date: September 18, 2014, Accepted Date: December 15, 2014, Published Date: December 24, 2014

Copyright: (c) 2015, Andrés Fontalba-Navas et al., This is an open-access article distributed under the terms of the Creative Commons Attribution License, which permits unrestricted use, distribution, and reproduction in any medium, provided the original author and source are credited.

\begin{abstract}
The approach to Problematic Internet Use must start from previous levels of intervention, such as prevention and health promotion. Young people are a very susceptible group to work with in the early stages of this disorder. Our aim is to develop an intervention model based on prevention, aimed at adolescents in high school. This intervention has been carried out 26 occasions in a total of 22 high schools in an area of 150.000 inhabitants, estimating a global intervention in 1200 students. Acceptance by centers, professionals and students has been high, its continuation being requested in Health Promotion programs.
\end{abstract}

Keywords: Problematic Internetuse; Health promotion;

Adolescents

\section{Introduction}

In today's society, our way of life has changed, largely because of the influence of new technologies. In developed countries television has been, in recent years, the most influential media. Currently, however, other technologies have been introduced in our lives at high speed. Thus, today we live with large doses of not only television but also Internet, mobile phones and video games, mainly. Internet is a global phenomenon, and its influence has increased steadily in recent decades. It has become a significant component of contemporary life for all age groups. At present, the rapid emergence of online interactions provides new possibilities to exchange information, to provide support or to have conversations between people who otherwise could not be interconnected. However, the Internet has its own advantages and disadvantages [1]. Problematic Internet Use remains an ill-defined and heterogeneous construct, however two features appear fundamental to its conceptualization. The first pertains to the aspects of Internet use, described as excessive or compulsive, along with preoccupation with and loss of control over use of the Internet. The second refers to various adverse consequences of spending too much time on the Internet, such as neglecting social activities, relationships, health and work or school duties, and altering sleep and eating habits in a detrimental way [2]. The development of internet addiction follows the classic pattern of any addictive behavior, similar to what occurs with substance abuse or compulsive behaviors [3]: 1) excessive use, often associated with a loss of sense of time or a neglect of basic drives, 2) withdrawal, including feelings of anger, tension, and/or depression when the computer is inaccessible, 3) tolerance, including the need for better computer equipment, more software, or more hours of use, and 4) negative repercussions, including arguments, lying, poor achievement, social isolation and fatigue.
Internet Addiction can be defined as an inability to control one's use of the internet which leads to negative consequences in daily life. The terms 'compulsive internet use', 'pathological internet use', 'problematic internet use', etc., were usually considered as the synonyms of IA, although their points of view may be different [4]. Internet use can be pathological, and the percentage of addicted people is increasing while people become dependent on technology and Internet continues to develop [5].

Adolescents are a vulnerable population group. Life stress from interpersonal relationships and school are correlated positively with Internet Addiction in adolescents, and there is a positive correlation with anxiety [6]. Problematic Internet Use was associated with sleep problems including subjective insomnia and poor sleep quality too [7]. Adolescents are also vulnerable to misuse of this technology if they have not been taught how to use it adequately or if they are without supervision when using it. The approach of misuse of internet must start from previous levels of intervention, such as prevention and health promotion. Young people are a very susceptible group to work with in the early stages of these kinds of disorders, in detection and in prevention. The estimated prevalence of this problematic behaviour in Spanish adolescents is around 5 percent [8]. There are other studies in our epidemiological environment that describe this issue, such as research developed in Madrid by the organization "Protect them". Through the study on "Child Safety and Morals of Children on the Internet", we can conclude that all children use the Internet regularly and consistently. The connection time is moderate. Thus, $65 \%$ of children are connected less than 5 hours a week. $66 \%$ of children use the Internet as a leisure tool, leaving in the background its wide range of information, $11 \%$ of children who are connected, are developing characteristics of Internet Addiction Disorder, 50.5\% of those under only find the information they want sometimes or rarely, which highlights their lack of skills to function successfully in the network [9].

The study on "Child Safety and Habits of Children in the Use of Mobile Telephony"[10], it was noted that: $24 \%$ of children make calls 
Citation: Fontalba-Navas A, Marin-Ollala M, Gil-Aguilar V, Rodriguez-Hurtado J, Rios-Garcia G, et al. (2015) Mental Health Promotion: Prevention of Problematic Internet Use among adolescents. J Psychiatry 18: 218. doi:10.4172/2378-5756.1000218

Page 2 of 3

and $50 \%$ send text messages (SMS) daily. The same study demonstrated that $30 \%$ of children who use mobile phones have already purchased games for it, $72 \%$ of children report having received SMS messages inviting them to participate in sweepstakes or gambling, $28 \%$ felt overwhelmed and $10 \%$ say they have been "fatal" when forced to do without their mobile, and $11 \%$ claim to have lied to their parents and even stolen money at some stage to recharge the balance. In the study on "Video Games, Children and Parental Responsibility" [11], it was noted that during school days, $9 \%$ of children engaged in play between 1 and 2 hours. At the weekend, 23\% play more than 2 hours, $57 \%$ use pirated games, $27 \%$ discussed with their parents for the amount of time spent playing, $14 \%$ of respondents say they are "hooked" on a video game, $11 \%$ recognize that video games can make them more violent and $57 \%$ of children play games recognize where it is damaged, torture or kill people. In conclusion, the high prevalence of this disorder and its possible long-term consequences requires the development of preventive activities in this susceptible population.

\section{Mental Health Promotion}

The promotion of mental health has important health benefits on individuals and generally in society, promoting the welfare and quality of life of the population. The development of activities to promote mental health involves the creation of individual, social and environmental conditions that enable optimal psychological and physiological development [12]. According to the World Health Organization, mental health is a state of being in which the individual realizes his or her own abilities, can cope with the normal stresses of life, can work productively and fruitfully, and is able to make a contribution the community [13]. In fact, a change of perspective is required in mental health care systems. This new perspective needs to come away from experiences focused almost exclusively on the provision of services and concentrate and take into account the promotion of mental health. Therefore, the strategy of promoting mental health has always been a priority in our area, establishing objectives and inter-sartorial tagging activities, aimed at encouraging greater well-being and quality of life of the population [14]. We propose an activity of prevention of problematic internet use in adolescents. To encourage participation, we have chosen high schools as the best place for this activity to be carried out. In health promotion it is necessary to reach the largest group of the susceptible population. For this reason we have developed the activity in all secondary schools in our area (southeast Spain, 150,000 inhabitants)

Our main aim is not to convince the teenager of our point of view. In fact, they should dissent when they disagree and they can give an opinion in their original perspective. Indeed Adolescents have the possibility to maintain their judgments respecting tolerance and to incorporate new knowledge about healthy behaviors. In this sense, this type of intervention encourages active learning, with a high level of interaction between participants. The professionals try to develop psychological defense strategies in the adolescents against this harmful behavior with emphasis on early detection.

\section{Early Detection}

In working with adolescents the need for early detection of warning signs is very important, and is secondary to a possible timely intervention by qualified personnel. Alarm signals in problematic internet use that can be detected $[15,16]$ :

- Neglect of duties
- Loss of sense of time and focused attention

- Decreased academic performance

- Decreased sleep time (used to connect to the Internet)

- Reactions include irritation if interrupted or if time limits for use are set

- Anxiety and impatience with slow connections or when unable to find something or someone online.

- Feelings of euphoria and abnormal activation when in front of the computer.

- Abandonment of hobbies, and leisure activities in order to spend more hours at the computer

- Meetings with increasingly rare friends (even real friends are abandoned in order to connect with virtual friends).

In our health promotion activity we explained these warning signs to the adolescents, because the negation of this problematic behavior is very usual. On the other hand, early detection enables an intervention in the early stages of this disorder. A positive perspective of internet use is very important, because if we only use a negative view of this behavior in adolescents it is possible that we induce it. Thus the title of the intervention is "Adequate use of internet"

\section{Model of Intervention}

- Name of activity: workshop "adequate use of internet"

- Target: students in the 3rd course in high school in north almería (14-15 years old).

- Number of sessions: 1 session

- Session duration: 2 hours.

- Number of participants: 1 group of 30 participants (maximum).

- Place: classroom of secondary schools.

- Teachers: professionals from the mental health from north almeria health area

\section{Content and Schedule}

-1st: 20 min. Presentation of the session.

A1-One-concepts: "Internet" and "Addiction" (types and brief description).

B1- Differences between addictive behavior and normal behavior. The concept of addiction and types is presented on a screen

\section{C1-Problematic use of internet - Expositive and Participative Part}

-2nd: Put pieces of paper with descriptions of types of behavior in a box: addictive and not addictive behaviors, according to the definition (distributed $=50 \%$ ). Each student takes one and reads it and together they decide if it corresponds to one type or another. $20 \mathrm{~min}$

-3rd: Questions and answers on the screen: Is it possible to have an addictive behavior related to the use of Internet? How do we know if we carry out addictive use of Internet? Narrative descriptions of the addictive behavior in the use of internet - $10 \mathrm{~min}$

-4th: Differences between addictive use and a healthy use of Internet. - $20 \mathrm{~min}$ 
The adolescents are divided into 2 groups in which they reflect on and prepare the next subjects using "role play":

Group 1: addictive internet use behavior.

Group 2: healthy internet use behavior.

-5 th. Differences in the addictive and not addictive behaviour in the use of Internet during the "role play". Exhibition of the role play of each group.- 20 min (10 minutes per group)

-6th Expo $10 \mathrm{~min}$. Expository conclusions.

\section{Results and Future Lines of Investigation}

The activity has been carried out on 26 occasions in a total of 22 high schools, estimating a global intervention in 1,200 students. Acceptance by centres, professionals and students has been high, its continuation being requested in Health Promotion programs, it has also been evaluated by a satisfaction questionnaire. We have preliminary data from the last two high schools in which this activity has been carried out. Before the activity we measured the problematic use of chat, internet, mobile phone and email with an auto-evaluation questionnaire, and then factored in the results by age group and sex, in a sample of 277 participants.

The prevalence of Problematic Use of Internet in this sample was $5.89 \%$, similar to other studies, without differences by sex. But an intervention in health promotion focuses on the entire population at risk, so we propose to carry out our activity in all the adolescents in our area. Most adolescent explain that they usually sleep less than 7 hours per day and that they spend too much time using new technologies. In contrast, they do not assume that this is a behavior problem. In this sense, this research considers that adolescents need a different approach, and different focus. For this reason, professionals should consider talking about positive habits to this population as this will have better results. In this sense, this work will try to overcome the negative image of mental health services and illnesses and will build a new perspective based on the promotion of healthy habits and activities. As regards to future lines of investigation, the characteristics of more effective interventions including: teaching skills, focusing on positive mental health; balancing universal and targeted approaches; starting early with the youngest children and continuing with older ones; operating for a lengthy period of time and embedding work within a multi-modal/whole-school approach which includes such features as changes to the curriculum including teaching skills and linking with academic learning, improving school ethos, teacher education, liaison with parents, parenting education, community involvement and coordinated work with outside agencies. Interventions were only effective if they were completely and accurately implemented: this applied particularly to whole-school interventions which could be ineffective if not implemented with clarity, intensity and fidelity [17]. Finally, an interesting line of research to assess the impact of the activity in the general population and measure the appropriate use of information technology and communication that we want to promote is open.

\section{References}

1. Sinkkonen HM, Puhakka H, Meriläinen M (2014) Internet use and addiction among Finnish adolescents (15-19 years). J Adolesc 37: 123-31.

2. Spada MM (2014) an overview of problematic internet use. Addict Behav 39: 3-6.

3. Block JJ (2008) Issues for DSM-V: Internet addiction. The American Journal of Psychiatry 165: 306-307.

4. American Psychiatric Association (2010) APA announces draft diagnostic criteria for DSM-5: New proposed changes posted for leading manual of mental disorders.

5. Gioka S, Kefaliakos A, Ioannou A, Mechili A, Diomidous M (2014) Hospital based Treatment for Internet Addicts. Stud Health Technol Inform 202: 279-82.

6. Tang J, Yu Y, Du Y, Ma Y, Zhang D, et al. (2014) Prevalence of internet addiction and its association with stressful life events and psychological symptoms among adolescent internet users. Addict Behav 39: 744-7.

7. Lam LT (2014) Internet gaming addiction, problematic use of the internet, and sleep problems: a systematic review. Curr Psychiatry Rep. Apr 16: 444.

8. Lopez-Fernandez O, Freixa-Blanxart M, Honrubia-Serrano ML (2013) The problematic internet entertainment use scale for adolescents: prevalence of problem internet use in Spanish high school students. Cyberpsychol Behav Soc Netw. 16: 108-18.

9. Child Safety and Morals of Children on the Internet (2002) Organization protegeles. Child Protection Services Madrid.

10. Child Safety and Customs of Children in the use of Mobile Telephony (2005) organization protegeles. Child Protection Services Madrid.

11. Video Games, Children and Parental Responsibility (2005) organization protegeles. Child Protection Services Madrid

12. III Andalusian Health Plan 2003-2008 "Andalucía health: building our future together."Andalusian Health Service.

13. II Quality Plan Andalusian Public Health System 2005-2008 "Walking towards excellence."Andalusian Health Service.

14. II Comprehensive Plan for Mental Health (PISMA) 2008-2001.2 Andalusian Health Service.

15. Young K (1998) Internet Addiction: The Emergence of a New Clinical Disorder. Cyber Psychology \& Behavior 1: 237-244.

16. Echeburua E, Corral P (2010) Addiction to new technologies and to online social networking in young people: A new challenge. Adicciones 22: 91-96.

17. Weare K, Nind M (2011) mental health promotion and problem prevention in schools: what does the evidence say? Health Promot Int 26 Suppl: 29-69. 